Habitação própria e a justiça do Estado de direito nas execuções hipotecárias

Vera Martins

Julho 2018

WP $\mathrm{n} . \mathrm{0} 2018 / 06$

DOCUMENTO DE TRABALHO

WORKI NG PAPER

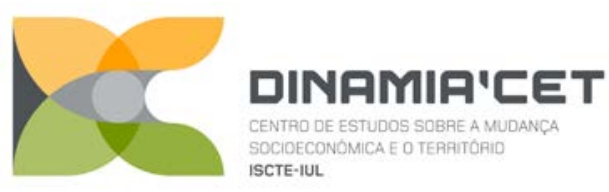

ISCTE IUL

Instituto Universitário de Lisboa

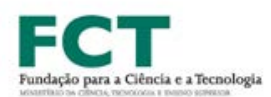




\title{
Habitação própria e a justiça do Estado de direito nas execuções hipotecárias
}

\author{
Vera Martins ${ }^{1}$ \\ WP n. 0 2018/06
}

DOI: 10.15847/dinamiacet-iul.wp.2018.06

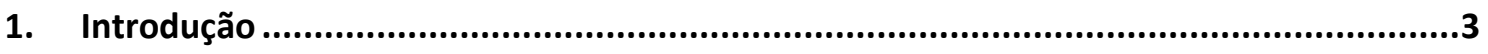

2. 0 incumprimento do crédito à habitação e a legislação protectora do devedor...............4

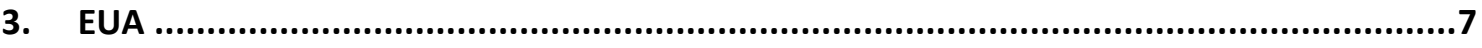

3.1. Literatura sobre processo judicial e protecção: resultados ………………................... 9

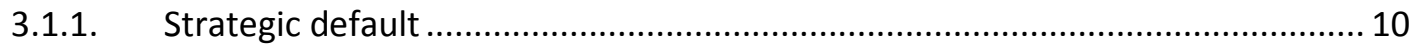

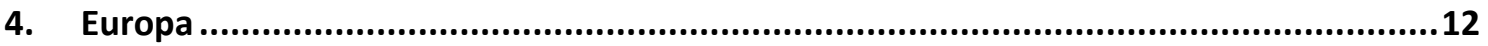

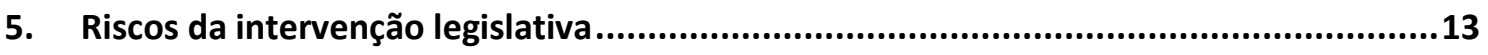

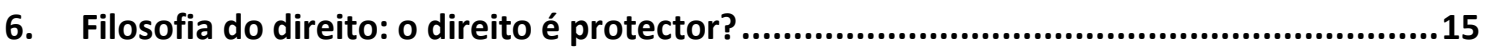

6.1. A realização do direito e a vinculação do juiz à lei..................................................... 17

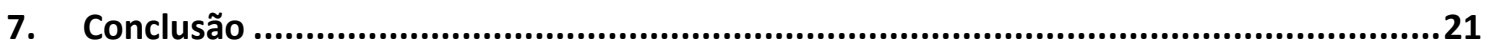

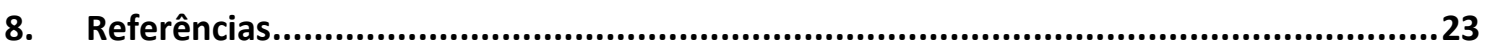

\footnotetext{
${ }^{1}$ Faculdade de Ciências Socias Humanas - FCSH, Programa Doutoral em Estudos sobre a Globalização da Universidade Nova de Lisboa - UNL, e Dinâmia'CET-IUL do ISCTE-IUL. E-mail: veramartins10@gmail.com
} 


\section{Habitação própria e a justiça do Estado de direito nas execuções hipotecárias}

\section{SUMÁRIO}

O presente artigo visa questionar a classificação econométrica simplista - binária - do impacto da legislação sobre as execuções hipotecárias - em protective e não protective - por conduzir à afirmação do sistema jurídico de direito continental (civil law) como mais protector do que o sistema jurídico de common law, porquanto no direito continental se garante a existência de um processo judicial - o que não acontece sempre nos sistemas jurídicos de common law.

Argumenta-se no sentido de que só o conhecimento da prática judiciária - o momento da realização do direito - permitirá afirmar se existe, nomeadamente em Portugal, uma maior protecção face aos sistemas de common law - que privilegiariam os non-judicial settlements porque a duração do processo judicial protege o devedor hipotecário.

Pretende-se articular a análise econométrica da dimensão jurídica com a filosofia do direito. Questionamos a falta de alinhamento da função dos tribunais - administrar a justiça em nome do povo (artigo 202..$^{\circ}$ da CRP) - com a aceleração processual (abandonando o conceito de tempo razoável), com o automatismo (que não se coaduna com a realização da justiça no caso concreto), com o afastamento de facto do devedor hipotecário dos autos (não é obrigatória a constituição, mesmo que oficiosa, de um advogado), com a atribuição de tarefas judiciárias ao Agente de Execução, por colidirem com a função de validade crítica que cabe hoje aos tribunais, conforme defende Castanheira Neves.

\section{PALAVRAS-CHAVE}

Execuções Hipotecárias, Tempo da Justiça, Protecção, Filosofia do Direito 


\section{INTRODUÇÃO}

O objectivo do presente artigo é, em primeiro lugar, revelar imprecisões na classificação econométrica da realidade jurídica, incentivando o debate em torno da efectiva protecção do credor ou devedor em detrimento de uma generalização redutora que assume que os sistemas de direito continental protegem o devedor hipotecário, enquanto os sistemas de common law não garantem a mesma protecção.

Relativamente a este primeiro objectivo, os dados são, conforme clarifica Karen Pence (2003), reveladores, pois apontam para que cerca de $40 \%$ dos estados nos EUA sejam estados "judiciais" (ou mais protectores). De acordo com a classificação já banalizada - nos EUA os estados ou são protective for borrower ou non-protective for borrower - quase metade dos estados nos EUA são "judiciais" sendo, por isso, estados protectores, logo a ideia corrente de que os EUA são claramente não protectores constitui uma falácia.

Ainda no que diz respeito a este primeiro aspecto, cumpre realçar o seguinte: nos sistemas de direito continental (civil law), a existência de processos judiciais com prazos muito curtos também deita por terra uma visão simplista da dimensão jurídica, pois os processos judiciais poderão não proteger de forma efectiva o devedor hipotecário.

Em segundo lugar, este artigo pretende abrir caminho para uma reflexão mais aprofundada sobre a necessidade de convocar a filosofia do direito em momentos críticos e de grande complexidade, fruto de abruptas mudanças económicas e sociais como foi o caso da crise financeira global de 2008. O equilíbrio entre credores e devedores e o equilíbrio na protecção a conferir a cada um tem sido objecto de análise por parte da teoria legal em momentos históricos diversos. Veja-se matéria, Menezes Cordeiro (2012) evidenciando o caso paradigmático da antiga tradição romana. Apresenta-se, assim, o argumento de que os estudos económicos cumprem melhor a sua função quando articulam variáveis sócio-culturais e até institucionais para demonstrar que a própria economia possui os recursos para uma análise mais explicativa da complexidade social. Pence (2003) invoca o contexto do aparecimento do redemption period ${ }^{2}$ (período em que ainda é possível reaver a casa) e o contexto do deficiency judgement ${ }^{3}$ (o direito de perseguir outros bens para além da casa) para uma explicação mais completa da relação de forças no equilíbrio entre credor e devedor hipotecários.

\footnotetext{
${ }^{2}$ De acordo com Cutts \& Merril (2008), é um período de tempo mais favorável para o devedor hipotecário reaver a casa, pois continua a habitá-la (embora na maioria dos estados dos EUA perca o título relativo ao direito de propriedade), mas não está obrigado ao pagamento das prestações do empréstimo bancário durante este período.

${ }^{3}$ De acordo com Vicente (2013), é o direito do credor a perseguir outros bens do devedor para além da casa tendo em vista o ressarcimento total da dívida apresentada pelo credor.
} 
Deste modo, a conciliação da literatura econométrica com a literatura da área do direito e da filosofia do direito é um contributo para encontrar lentes de análise academicamente mais robustas e mais explicativas da realidade social. A abordagem interdisciplinar clarifica e alarga o cenário de soluções possíveis, relativas à habitação, ao mercado da habitação e à gestão do incumprimento dos empréstimos hipotecários, atenta a evidência de que este é um mercado transmissor de grande instabilidade, também social ("the tendency of housing market to display extremes") (Bramley; Munro; Pawson, 2004). Este artigo não visa uma análise global, e necessariamente mais ambiciosa, do conjunto das políticas de habitação (que teria de incluir o sector da habitação social, cooperativo e o arrendamento privado). $\mathrm{O}$ foco deste artigo cinge-se, pois, ao mercado da habitação própria e aos "inevitáveis incumprimentos" conforme enfatiza Leitão Marques (Marques, 2004), e sobretudo ao desenrolar dos processos executivos para pagamento coercivo das dívidas hipotecárias. O objectivo é o clarificar o papel do Estado (saber se protegeu ou não os devedores), por via da função jurisdicional.

Bourdieu (2012) debruçou-se sobre aquilo a que chamou o mercado da habitação, procurando esclarecer precisamente qual é o papel do Estado, adiantando que é "uma coisa que parece insignificante, mas na qual se joga qualquer coisa de fundamental". Ao construir um objecto empírico através dos processos judiciais em que são executados os proprietários de uma habitação própria e permanente, execuções que decorrem no contexto de uma crise financeira e económica à escala global, pretende-se indagar o efectivo grau de proteção concedido.

É consensual que a crise iniciada em 2008 conduziu a um aumento significativo de falências e desemprego, agravando a recessão, e o mercado imobiliário foi severamente atingido (Campilho, 2011). Estamos, pois, perante um contexto de turbulência financeira em que muitas famílias dotadas de um direito de propriedade, mas devedoras de um empréstimo bancário, perderam a sua casa. Com o caso concreto do conflito - entre um direito de crédito e um direito de propriedade sobre a casa própria - há que clarificar qual a efectiva protecção atribuída a credores e devedores e para tal construir "[um] objecto[s] empírico[s] contemporâneo[s] de forma a encontrar o Estado sob o seu escalpelo.” (Bourdieu, 2012).

\section{O INCUMPRIMENTO DO CRÉDITO À HABITAÇÃO E A LEGISLAÇÃO PROTECTORA DO DEVEDOR}

Os estudos económicos, sociológicos, e sobretudo sócio-legais sobre o incumprimento do crédito à habitação são escassos a nível Europeu. O mesmo não se poderá dizer relativamente aos EUA, onde estes estudos são em grande número e se realizam desde há muitos anos, o que lhes confere uma consistência analítica assinalável (ECB, 2009).

\footnotetext{
DINÂMIA'CET - IUL, Centro de Estudos sobre a Mudança Socioeconómica e o Território do Instituto Universitário de Lisboa (ISCTE-IUL)

Sala 2W4 - D | ISCTE-IUL - Av. das Forças Armadas 1649-026 Lisboa, PORTUGAL 
São apontados como factores de dificuldade acrescida à elaboração - na Europa - de estudos interdisciplinares sobre incumprimento do crédito à habitação - quer sob a forma de relatórios quer sob a forma de artigos científicos comparativos entre os vários Estados-membros - a diversidade de sistemas jurídicos e a falta de dados comparáveis ao longo do tempo (ECB, 2009). No entanto, como é sabido, também nos EUA existe diversidade relativamente aos sistemas jurídicos dos diversos Estados.

O relatório Housing Finance in the Euro Area (ECB, 2009) procurou de algum modo colmatar esta lacuna na investigação europeia. $\mathrm{Na}$ impossibilidade de realizar um estudo quantitativo, elaborou-se um estudo qualitativo focando procedimentos para a insolvência e execução hipotecária (incluindo a não-judicial), para além de se abordar variáveis estritamente financeiras, tais como as taxas de juro e outras características dos empréstimos hipotecários (maturidades, loan to value ratio etc). Logrou-se assim alcançar uma comparação mais rica entre o bloco europeu e os EUA.

A relevante magnitude da crise do imobiliário, sobretudo depois de 2008 , conduziu a um elevado número de execuções hipotecárias, tal como se descreve no relatório Housing Finance in the Euro Area (2009) e é enfatizado por Berry et al. ("a further unwinding of the crisis with negative spillover effects on the economies of the major Western nations") (Berry, 2010). Atenta ainda a premente dificuldade no acesso à habitação, importa aproveitar a diversidade de contextos sócio-culturais e soluções jurídicas, nomeadamente na gestão do incumprimento do crédito hipotecário, para reflectir e colher ensinamentos sobre as várias abordagens no acesso à habitação. Não tem sido suficientemente intenso o debate académico interdisciplinar em torno das consequências da massificação do homeownership, sendo por isso necessário aprimorar o tratamento estatístico desta realidade, sobretudo a nível judicial. Será assim possível estudar mais rigorosamente quais as medidas adequadas para mitigar as graves repercussões sociais da instabilidade do mercado imobiliário, também a nível social.

É um facto que nem todos os países na União Europeia foram afectados com a mesma gravidade pela crise de 2008, mas para alguns (Portugal, Espanha, Grécia) (Pittini et al., 2015) o número de incumprimentos e execuções hipotecárias tem vindo a traduzir-se num problema social e político crucial, na medida em que em última análise pode afirmar-se que não está apenas em causa a violação do direito à habitação constitucionalmente previsto; trata-se, também, da ruptura de um vínculo de pertença dos cidadãos relativamente ao Estado, por via da "desvalorização" do seu direito à propriedade. É sabido que o direito de propriedade e o crédito são pilares das democracias liberais, conforme salienta Streeck (2011) no artigo The Crises of Democratic Capitalism e são-no enquanto expoentes de um processo de emancipação colectiva. (Wieacker, 2010; Villey, 2005). A literatura destaca o papel agregador da casa enquanto refúgio

\footnotetext{
DINÂMIA'CET - IUL, Centro de Estudos sobre a Mudança Socioeconómica e o Território do Instituto Universitário de Lisboa (ISCTE-IUL)

Sala 2W4 - D | ISCTE-IUL - Av. das Forças Armadas 1649-026 Lisboa, PORTUGAL 
físico e simbólico (Levinas, 2011), centro de relações sociais (educação, trabalho, saúde, cultura, género e lazer) e até, mais recentemente, enquanto activo financeiro de longo prazo e relevante complemento da pensão (Doling \& Ronald, 2010). Quando um número elevado de agregados familiares é atingido (em 2012, cerca de 146.000 agregados familiares estavam em situação de incumprimento) (Pordata, 2015) sem que o Estado consiga apresentar uma estratégia cabal, é o vínculo de pertença ao Estado que é fortemente atingido.

Acresce que o incentivo à aquisição de habitação própria é uma política pública paradigmática desde o início dos anos 80 mas que continua actual. David Cameron em 2015 ainda defendia este desiderato (Guardian, 2015). Também em Portugal, o Presidente do Instituto Nacional de Habitação, em entrevista ao jornal Expresso (2015) revelou os elevados montantes despendidos pelo Estado português no crédito bonificado para aquisição de habitação própria; veja-se ainda o estudo sobre Finança e habitação (Santos, Teles, \& Serra, 2014).

$\mathrm{O}$ direito à propriedade alicerçado num crédito hipotecário tem raízes importantes também no contexto da propriedade rural; aí o objectivo era que o agricultor pudesse ter acesso a um asset que lhe permitiria a sobrevivência e, simultaneamente, um investimento sólido. Trata-se portanto de um marco - a aliança entre direito de propriedade e crédito hipotecário - no processo societal de passagem da sobrevivência para o investimento por parte "dos muitos" - e já não apenas de "poucos" (Arendt, 2005) - assegurando mais controlo sobre as suas próprias vidas (Lefebvre, 2011).

No estudo "The Effect of Foreclosure Regulation: Evidence for the US Mortgage Market at State Level” (Vicente, 2013), uma encomenda do Banco de Espanha, Vicente chama a atenção para a necessidade de estudar o pluralismo legislativo nos EUA. Atenta a riqueza de soluções aí existentes, no que diz respeito ao incumprimento do crédito hipotecário, estas devem ser cuidadosamente analisadas. Este autor afirma mesmo que as conclusões a que se chegar com esse estudo "could be of interest to the policy-makers of any country suffering the effects of a housing market collapse".

Estudar a legislação sobre execuções hipotecárias nos EUA será, pois enriquecedor para os países europeus, por isso vários autores portugueses o vêm fazendo - incluindo o Banco de Portugal (BdP, 2009) que o faz de forma detalhada, analisando o impacto da crise financeira em Portugal. Veja-se também, entre outros, o estudo de Spang-Hanssen (2009) sobre o caso dinamarquês, um mercado hipotecário bastante desenvolvido. Justifica-se assim a importância de se partir da análise das execuções hipotecárias dos EUA no âmbito deste artigo.

Portugal, sendo um dos países mais afectados com a crise financeira iniciada em 2008, não pode alhear-se desta discussão com um peso central na vida das pessoas e na afirmação do Estado enquanto detentor de um poder efectivo na condução da estratégia para o acesso à

\footnotetext{
DINÂMIA'CET - IUL, Centro de Estudos sobre a Mudança Socioeconómica e o Território do Instituto Universitário de Lisboa (ISCTE-IUL)

Sala 2W4 - D | ISCTE-IUL - Av. das Forças Armadas 1649-026 Lisboa, PORTUGAL 
habitação - quer a que é promovida pelo Estado quer a que é promovida pelo mercado. Abordam-se de seguida os conceitos econométricos utilizados nos EUA e comparar-se-á posteriormente, ainda que de forma sumária, a realidade americana com a europeia.

\section{EUA}

Os estudos econométricos nos EUA classificam a legislação que rege as execuções hipotecárias de forma pragmática, como "friendly for lender" quando não existe a obrigatoriedade de um processo judicial, e "friendly for borrower" quando existe a obrigatoriedade de um processo judicial (Pence, 2003). Deste modo, com o objectivo de se apurar o impacto da legislação no incumprimento, a legislação - a dimensão jurídica - é transposta para os modelos econométricos como uma variável regulatória (dummy variable: 0 ou 1). Ou seja, é-lhe atribuído o valor " 0 " ou valor "1" para diferenciar entre legislação protectora e não protectora.

Vicente (2013) segue a terminologia de Pence (2003), mas adopta a expressão protective for borrower (quando existe processo judicial) e non-protective for borrower (quando não se exige processo judicial), terminologia que seguiremos, embora com algumas cautelas. Porém, ambos clarificam que se acrescentam dois outros critérios para mitigar esta dualidade simplista na classificação econométrica da legislação - para permitir que seja possível uma certa gradação na protecção. Assim, sempre que a execução implica um processo judicial, e permite um período para o resgate da casa (redemption period), considera-se que estamos perante um estado muito protector do devedor (very protective) e sempre que não implica um processo judicial mesmo que permita esse período para o resgate da casa, é um estado qualificado como nonprotective. Doravante neste artigo relativamente a este recurso, dada a dificuldade em enquadrálo no direito português usar-se-á a expressão "período para o resgate da casa".

Já um estado que não exige nem o processo judicial nem permite o redemption period é very non protective. Assim, a categoria do deficiency judgement - a possibilidade de perseguir outros bens para além da casa -, esta categoria, dizíamos, não é ignorada mas também não se enquadra de forma directa nesta classificação, o que é relevante. Trata-se de um recurso importante pois é um instrumento que dá ao credor a possibilidade de perseguir outros bens do devedor; este é sem dúvida um mecanismo legalmente previsto na grande maioria dos estados (EUA), mas a literatura esclarece que na prática este mecanismo raramente é utilizado (Pence, 2003): "contrary to popular opinion the majority of states (40 out of 51) allow for a deficiency judgement and are classified as recourse states (78\% of the population)" e Leitão também realça

\footnotetext{
DINÂMIA'CET - IUL, Centro de Estudos sobre a Mudança Socioeconómica e o Território do Instituto Universitário de Lisboa (ISCTE-IUL)

Sala 2W4 - D | ISCTE-IUL - Av. das Forças Armadas 1649-026 Lisboa, PORTUGAL 
este aspecto (Leitão, 2015). No entanto, o que os dados empíricos revelam é que é desencorajado o seu uso por via do custo, concluindo-se então que a regra vigente "de facto" é a de não se executarem outros bens do devedor para além da habitação penhorada.

Não existe - como acabou de se clarificar - uma proibição generalizada do deficiency judgement, mas este recurso que permitiria perseguir outros bens do devedor não é utilizado com frequência. Pence (2003) observa que esta possibilidade, por ser formalmente conferida ao credor, traduz-se então numa ameaça que reforça substancialmente o poder negocial dos credores: "the threat of a deficiency judgment can be used to obtain concessions from the borrower".

Razões histórico-culturais justificam a parcimónia na utilização de facto deste recurso por parte do credor. É que durante a Grande Depressão foram cometidos abusos por parte dos credores ao retirar, aos devedores hipotecários incumpridores, a sua habitação, perseguindo ainda os restantes bens do devedor. Em reacção a isto, ainda hoje nove estados da Costa Oeste proíbem este recurso nas situações típicas de incumprimento da dívida hipotecária, por exemplo na Califórnia, relativamente às situações típicas de habitação própria [encurtei a frase] (Pence, 2003).

Concluímos, então, que a literatura econométrica incorporou o discurso jurídico na sua análise através da categorização em protective e não protective, consoante se exige um processo judicial, se atribui a possibilidade de reaver a casa e até se é possível perseguir outros bens do devedor para além da habitação penhorada - o recurso mais debatido no espaço público em Portugal - quando o valor comercial da habitação é inferior ao valor do crédito hipotecário.

Constata-se que nos modelos referentes ao impacto da legislação no incumprimento, a redução da complexidade foi assim introduzida: os economistas muniram-se de recursos pragmáticos na gestão econométrica da realidade jurídica, baseando-se afinal na duração do processo para afirmar que um processo longo protege o devedor e um processo curto protege o credor. É no âmbito desta dicotomia apriorística que se atribui desde logo ao processo judicial um carácter protector do devedor: os processos judiciais são aparentemente mais demorados na resolução do conflito entre credor e devedor hipotecários (Clauretie, 1987; Clauretie \& Herzog , 1990; Cutts \& Merrill , 2008; Meador , 1982).

No entanto, do ponto de vista do direito teremos de questionar: o processo judicial é a garantia efectiva da protecção do devedor? 


\subsection{Literatura sobre processo judicial e protecção: resultados}

Atendendo a que os principais factores que condicionam a propositura de uma execução judicial são o tempo necessário para resolver esse litígio e os custos processuais - para além da imprevisibilidade, ou seja, o risco do incumprimento - conclui-se que as normas legais que regulam estas dimensões desempenham um papel determinante no incumprimento e nas execuções hipotecárias.

Vicente (2013) no seguimento dos trabalhos realizados por Pence (2003), ao estudar o impacto, nos EUA, da legislação que regula as execuções hipotecárias aquando do incumprimento, conclui que "in the mortgage market lenders aim to maximize their profit on basis of their cost structure, which is partially dictated by the risk of not getting repaid", de acordo com a equação:

$$
P[\text { No Default }]\{(1+r) M\}+P[\text { Default }]\{E[z(D P)+M]-k\}-M=0
$$

em que $r$ é interest rate, $M$ é outstanding mortgage loan balance, $E$ é the expectations operator, $z$ é value since purchase, $D P$ é the down-payment e $k$ é the foreclosure cost for the lender.

Assim, o credor tem a capacidade de ajustar, nas condições oferecidas com o crédito, o risco de incumprimento - quer inicialmente quer na vigência do contrato - por forma a maximizar o lucro ou a minimizar o impacto do incumprimento. São vários os estudos que sustentam esta afirmação e serão sumariamente apresentados.

Veja-se Clauretie (1987) quando chama a atenção para o facto de que nos estados onde os custos para o credor são baixos (nomeadamente porque não se recorre a um processo judicial) o credor não terá incentivos para negociar com os "delinquent borrowers" pelo que, necessariamente, negociará menos com o devedor.

Já Clauretie e Herzog (1990) e Pence (2003) salientam que a legislação protectora do devedor impõe automaticamente taxas de juros mais altas e obrigações mais desfavoráveis para o devedor aquando do início da relação contratual, tais como: cláusulas mais restritivas e também maiores custos associados para o devedor. Claramente se depreende que a relação entre credor e devedor de um ponto vista geral - e não em cada caso concreto - consegue repercutir a dinâmica legislativa na dinâmica económica. Ou seja, face a cada alteração legislativa podem os credores ajustar as condições contratuais ao risco do incumprimento. Assim, conforme a equação bem demonstra, o credor tem a capacidade de repercutir no crédito as condições que lhe sejam impostas, por forma a garantir a sua margem de lucro. A introdução de cláusulas restritivas revela então um relevante meio de pressão psicológica sobre o devedor, mesmo que

\footnotetext{
DINÂMIA'CET - IUL, Centro de Estudos sobre a Mudança Socioeconómica e o Território do Instituto Universitário de Lisboa (ISCTE-IUL)

Sala 2W4 - D | ISCTE-IUL - Av. das Forças Armadas 1649-026 Lisboa, PORTUGAL 
não accionadas. Neste seguimento, Frade (2015) também alerta para o facto de que os devedores são "actores económicos menos profissionalizados e menos apetrechados para operar em mercados tão complexos como são os actuais mercados financeiros".

Relativamente a este equilíbrio na relação entre credor e devedor, Pence (2003) esclarece que o devedor não tem em conta a legislação relativa ao crédito hipotecário aquando da celebração do contrato, certamente nos mesmos termos em que o credor incorporou esse conhecimento nas cláusulas do contrato, (Frade, Lopes, Jesus, \& Ferreira, 2008).

Cutts and Merryl (2008) acrescentam até que os devedores nem estão cientes de quais as opções de que dispõem para fazer face ao incumprimento quando este acontece ou se avizinha, pelo que parece pouco plausível que conheçam a legislação sobre a acção executiva e suas garantias. Foi emblemática a afirmação de Vítor Bento (2011) de que «a criação de uma [tal] bolha especulativa é um processo típico de "loucura colectiva"» pois "um período de prosperidade funda comportamentos baseados em expectativas adaptativas (...) acabando por gerar a falsa convicção de que a valorização dos activos (financeiros e reais, como o imobiliário) é imparável." No âmbito do estudo dos fluxos de crédito (também para aquisição de habitação), o Banco de Portugal elenca alguns dos factores prevalecentes na materialização do risco de crédito, nomeadamente "o comportamento de manada (herd behaviour)", (Alves \& Ribeiro, 2011); este comportamento revela a falta de conhecimentos e de reflexão individual na contratualização dos empréstimos para aquisição de habitação.

\subsubsection{Strategic default}

Goodman e Smith, (2010); Mia et al. (2009) são peremptórios em afirmar a centralidade do processo judicial na protecção dos devedores, afirmando até que os processos judiciais mais longos são os mais protectores, e, quando cumulativamente se permite o direito de resgatar a casa (redemption period), o grau de protecção é ainda maior.

Mia et al. (2009) constata que nos estados onde existe processo judicial as taxas de execução são mais baixas. No entanto, deve tomar-se em atenção, conforme refere Ambrose et al. (1997) que a protecção do devedor pode conduzir a um maior número de casos de strategic default (incumprimento estratégico porque é motivado pela perda de valor comercial e não pela perda de rendimento), uma vez que o devedor se sente mais protegido contra a perda de valor comercial da casa no mercado.

O strategic default é, pois, um aspecto controverso; Guiso et al. (2009) chega à conclusão de que "the most important variables in predicting strategic default are moral and social considerations". Ao contrário do que se poderia supor, a decisão de incumprimento não é uma decisão puramente económica, embora a literatura encontre alguma correlação entre a

\footnotetext{
DINÂMIA'CET - IUL, Centro de Estudos sobre a Mudança Socioeconómica e o Território do Instituto Universitário de Lisboa (ISCTE-IUL)

Sala 2W4 - D | ISCTE-IUL - Av. das Forças Armadas 1649-026 Lisboa, PORTUGAL 
depreciação do valor comercial e o aumento do strategic default: "They find that no household would default if the equity shortfall is less than $10 \%$ of the value of the house" (Guiso , Sapienza , \& Zingales, 2009). Realça-se assim a complexidade de prever comportamentos utilizando recursos meramente econométricos, pois a casa não é tratada primariamente pelo devedor como um bem económico, mas como o centro da vida social (um activo social) e um investimento de longo prazo, portanto uma realidade diferenciada face a um mero bem de consumo

A indefinição sobre a protecção ideal a assegurar aos devedores hipotecários parece estender-se à verdadeira protecção conferida pelas execuções judiciais, tornando difícil captar qual o carácter da protecção do devedor assegurada pelo Estado: protege-se o consumidor ou a relação com um bem que é a sua habitação própria e permanente, com valor elevado mas com uma relevância bem diferente dos demais, pois agrega como vimos, dimensões relevantes para as políticas públicas. É sugestiva a terminologia de Saskia Sassen ao qualificar a engenharia financeira como "subterrânea", pois alerta para a opacidade da engenharia financeira associada ao mercado hipotecário (Sassen, 2017) e espelha a indefinição na protecção conferida pelo Estado.

Vicente (2013) parece concluir que a legislação mais protectora não contribui para a redução das taxas de execução. No entanto, Vicente também, sintomaticamente, afirma num outro momento que não é claro se a legislação protectora dos devedores reduz ou não a taxa de execuções "In summary, the question of whether foreclosure regulation to protect borrowers achieves the intended goals of curbing foreclosures and preserving homeowership is still unresolved". Outros autores afirmam que a legislação protectora reduz a taxa de execuções pelo que é necessário conhecer os processos judiciais para obter mais dados que ajudem a compreender esta relação, o que se pretende fazer relativamente a Portugal.

Concluindo, salta à vista nos estudos feitos nos EUA que, mesmo que de forma controversa, os economistas quando estudam o impacto da legislação no incumprimento dividem a legislação em mais ou menos protectora do devedor - contrariamente ao que se verifica na esfera do direito em que não é a partir da sua efectiva aplicação que se teoriza e actualiza o conhecimento. Assim, o sistema judicial de common law por secundarizar a vida judicial - acelerando aparentemente o processo - será pró-credor contrariamente ao sistema de direito continental que por fazer assentar a resolução do conflito entre credor e devedor hipotecários no processo judicial será pró-devedor.

Contudo, será o civil law pró-devedor mesmo nos casos em que os tempos da resolução do processo são mais baixos do que nos de common law?

\footnotetext{
DINÂMIA'CET - IUL, Centro de Estudos sobre a Mudança Socioeconómica e o Território do Instituto Universitário de Lisboa (ISCTE-IUL)

Sala 2W4 - D | ISCTE-IUL - Av. das Forças Armadas 1649-026 Lisboa, PORTUGAL 


\section{EUROPA}

O debate sobre a qualificação da protecção conferida ao devedor do crédito à habitação quer nos EUA quer na Europa caracteriza-se por não ser tão controvertido quanto se poderia pensar. Eis alguns dos pilares em que assenta a protecção: 1) o tempo de duração do processo: quanto menor o tempo mais favorável é a resolução do litígio para o credor; 2) quanto mais elevados os custos, mais desencorajada é a via judicial, logo maior é o desincentivo do devedor a recorrer ao tribunal, o que poderá conduzir à ausência do devedor no processo ou a uma sistemática negociação fora do processo; 3) o favorecimento da resolução do problema sem recorrer à via judicial, o que aparentemente beneficia o credor, por se traduzir em maior certeza jurídica e afastamento de um terceiro - o tribunal - com capacidade de interferir na definição dos termos do litígio.

O impacto da legislação sobre as execuções - sobretudo o impacto da legislação sobre a celeridade processual - é claramente o ponto fulcral da literatura económica e mais recentemente da literatura jurídica (Cabral, 2017; Verzelloni, 2017), quando salienta que o tempo é uma questão chave na economia, no dinamismo das empresas e no próprio funcionamento do mercado. Daí que o direito tenha sido recentemente impelido para a discussão da gestão do seu próprio tempo, integrando-se, assim, no processo de globalização financeira e económica e o correspondente desenvolvimento dos mercados financeiros, comercial e laboral (Gonçalves \& Guibentif, 2008). No entanto, o conceito de tempo "razoável” do processo judicial não é um conceito recente, está previsto desde há muito no Código de Processo Civil, mas pensado para que as partes sintam que as suas pretensões são ouvidas e atendidas num tempo aceitável, cumprindo-se assim o desígnio de realização da justiça previsto constitucionalmente (artigo 20. ${ }^{\circ}, n^{\circ} 4$ da Constituição da República Portuguesa).

Hoje, a globalização conduz a que haja uma convergência da legislação a nível global, apesar das ainda significativas diferenças nas soluções vigentes, tal como expressamente refere o relatório Housing Financial in the Euro Area (2009) a este propósito "despite ongoing attempts to attain global convergence in the design of consumer bankruptcy regulations, significant variations still exists". Constata-se, pois, neste documento que apesar da convergência existe aparentemente uma clivagem profunda no paradigma do civil law e do common law, sendo a duração do processo o factor diferenciador entre estes dois grandes blocos (EUA e EU). Previsivelmente, no sistema de common law existirão processos com menor duração por se privilegiar a resolução do problema fora dos tribunais; pelo contrário na EU o envolvimento dos tribunais aumentaria o tempo para resolução do problema, conforme explicitado supra.

\footnotetext{
DINÂMIA'CET - IUL, Centro de Estudos sobre a Mudança Socioeconómica e o Território do Instituto Universitário de Lisboa (ISCTE-IUL)

Sala 2W4 - D | ISCTE-IUL - Av. das Forças Armadas 1649-026 Lisboa, PORTUGAL 
Assim, fica demonstrado que também na Europa a protecção do devedor é aferida em função da duração do processo, sendo portanto claro que o credor enquanto player do mercado se rege por tempos curtos, precisando de celeridade, certeza e previsibilidade para afastar cenários de perda de valor do bem.

É também consensual que a presença do juiz garante a protecção do devedor por estar assegurado o respeito dos seus direitos enquanto parte processual, garantindo-se um "estatuto de igualdade substancial das partes", de acordo com o artigo $4 .^{\circ}$ do Código de Processo Civil.

Mais uma vez - ou seja agora no âmbito da análise da legislação europeia - se conclui que a categoria utilizada é a da duração do processo, pois é esta que determina se a legislação é pródevedor ou pró-credor. Ora sabendo-se que a maior parte dos países de civil law impõe a existência de um processo judicial, tem sido amplamente divulgada a ideia de que o civil law é necessariamente mais protector do que o sistema de common law. Neste último, a promoção de non-judicial settlements acelera a resolução do litígio. Porém, cabe-nos questionar, de forma desassombrada, se a aceleração dos processos no sistema de civil law ainda nos permite qualificar este sistema como protector.

\section{RISCOS DA INTERVENÇÃO LEGISLATIVA}

A investigação de Karen Pence datada de 2003 chama a atenção para realidades pouco examinadas na análise empírica, pois constata que as leis que regulam as execuções hipotecárias não são neutras:

"state foreclosure laws also affect these losses: foreclosures in some states are quick, lowcost procedures that provide scant protections for borrowers, while laws in other states confer substantial benefits on borrowers, and correspondingly large costs on lenders".

Estes estados com processos longos e onerosos seriam, pois, borrower-friendly states por terem leis "intended to protect homeowners in distress" (Pence, 2003).

Assim, Pence (2003) chama a atenção para o facto de que esta partilha de risco que onera os credores ter implicações não despiciendas para o mercado imobiliário: os maiores custos associados à cobrança da dívida hipotecária nos "defaulter-friendly foreclosure laws" implicam a subida das taxas de juro e de down-payment nos novos contratos, tornando o mercado imobiliário menos acessível a uma parte da população com menores rendimentos.

Pence (2003) conclui após aturada metodologia estatística para controlar as variações geográficas o seguinte: "I find that loan sizes are four to six percent smaller in states with defaulter friendly foreclosure laws, ou seja, há uma correlação entre a protecção conferida pelas

\footnotetext{
DINÂMIA'CET - IUL, Centro de Estudos sobre a Mudança Socioeconómica e o Território do Instituto Universitário de Lisboa (ISCTE-IUL)

Sala 2W4 - D | ISCTE-IUL - Av. das Forças Armadas 1649-026 Lisboa, PORTUGAL 
leis sobre execuções e o volume de crédito hipotecário: ao proteger os devedores a oferta de crédito hipotecário diminui e torna-se mais cara, afectando a própria procura.

Assim, a tese implícita é que as políticas públicas de habitação podem optar por garantir um acesso alargado ao crédito hipotecário para compra de habitação própria ou podem garantir protecção para os devedores com dificuldades económicas, mas não podem atingir estes dois objectivos simultaneamente.

Exposta a questão nestes termos, fica demonstrada a necessidade do Estado estabelecer quais objectivos a atingir: a massificação do crédito hipotecário ou a estabilização do incumprimento ou procurar um ponto de equilíbrio entre ambas. Verificamos que a dimensão legislativa terá de se articular com a prática judicial, pois as dinâmicas do mercado são analisadas a nível macroeconómico pelo poder executivo e legislativo, mas deverão incluir a análise dos resultados no momento da realização do direito, sob pena de incoerência. No entanto, também verificamos que as execuções hipotecárias repercutem a dinâmica dos mercados: a relação substantiva entre credor e devedor hipotecários é balizada por via legislativa, mas também o é por via contratual.

A literatura nos EUA também realça que as próprias leis sobre as execuções hipotecárias resultam de um processo de amadurecimento sobre a protecção e, por isso, a literatura mesmo quando afirma que os estados protectores são os que exigem processo judicial - por definição mais longo e oneroso - , utilizam, conforme referido, mais dois critérios para definir um estado como protector: a existência de um período em que é possível reaver a habitação (statutory right of redemption) e se existe a proibição de executar outros bens do devedor hipotecário (que não a habitação) para o total pagamento da dívida exequenda (deficiency judgment). Não tem sido devidamente aprofundado em Portugal o facto de estas duas variáveis regulatórias terem surgido no contexto de períodos económicos recessivos. Capone (1996) sustenta até que relativamente ao prazo para o resgate da casa (statutory right of redemption) discutido a propósito das crises do século XIX, a sua origem pode ter raízes tão antigas quanto a lei hebraica. De qualquer modo, na sua origem a ideia - de protecção - é a de que sobretudo em zonas agrícolas o credor teria de aguardar um ano - é este o período ainda vigente em nove estados dos EUA - para dar hipótese ao devedor de, após um mau ano agrícola - recuperar a propriedade agrícola. Não por acaso, a maior parte dos estados em que vigora esta protecção do devedor encontra-se geograficamente inserida na zona das Grandes Planícies.

Em relação à exigência de um processo judicial e à duração deste, determinou-se que em média a exigência de um processo judicial implicava uma duração superior em 198 dias face aos processos não judiciais. O estado do Maine (a judicial foreclosure state) demora mais 300 dias a 
resolver o conflito em tribunal do que o estado mais rápido (o Texas), de entre os que são power-of-sale (não-judicial) (Pence, 2003).

Para além da duração, Pence (2003) destaca a incerteza que um processo judicial acarreta, bem como os custos acrescidos. No entanto, está implícito na referida incerteza que o tribunal é um árbitro que impede a existência de abusos: "judicial foreclosure processes provide safeguard against lender excesses". Em Columbia foram os protestos dos activistas que permitiram aos devedores contestar "a predatory foreclosure in court". Fleischman (2002) conclui que os custos que as execuções com recurso a tribunal são o dobro de um processo power of sale.

Deste modo, sem estudos em Portugal que permitam aprimorar a grelha analítica da investigação sobre o incumprimento do crédito à habitação e sobre as execuções hipotecárias conhecendo com rigor os tempos, os custos e o perfil dos devedores - não avançaremos no conhecimento efectivo da realidade da habitação própria e permanente. Sendo a habitação central na estrutura económica e social - pilar na definição da constituição política - permitirá "distribuir os direitos e deveres fundamentais" e "determinar a divisão dos benefícios da cooperação em sociedade" (Rawls, 1971).

\section{FILOSOFIA DO DIREITO: O DIREITO É PROTECTOR?}

A economia, conforme explanado, não se inibe de categorizar a legislação como protectora e não protectora, mesmo quando simplifica e qualifica como protectora a existência de um processo judicial e não-protectora a dispensa da exigência de um processo judicial, isto em virtude da sua necessidade de operacionalizar os conceitos jurídicos.

A classificação - distinguindo entre protector e não-protector - tem por base o tempo. Contudo, não é abordado de forma esclarecedora a partir de quanto tempo é que há efectivamente protecção nem qual o alcance de protecção que as acções executivas permitem por se processarem nos tribunais. Veja-se o caso apresentado por Pence (2003) relativo ao prazo para o resgate da casa (redemption period) tão curto em que acaba por optar classificá-lo como não existindo redemption period, uma vez que os restantes estados apresentavam um período não de dias mas de meses. São operacionalizações da economia que levantam dúvidas, mesmo quando apresentadas de forma transparente.

Parece-nos portanto adequado procurar compreender como é que o direito se posiciona nesta discussão dominada pela ciência económica sobre a protecção do devedor. Menezes Cordeiro aponta no sentido de que o direito não é neutro, afirmando em 2012, no culminar da crise, que a tão propalada corrente da análise económica do direito não protege os mais fracos

\footnotetext{
DINÂMIA'CET - IUL, Centro de Estudos sobre a Mudança Socioeconómica e o Território do Instituto Universitário de Lisboa (ISCTE-IUL)

Sala 2W4 - D | ISCTE-IUL - Av. das Forças Armadas 1649-026 Lisboa, PORTUGAL 
(Cordeiro, 2012). Também Mangabeira Unger (1977) afirma - de forma peremptória, na linha da corrente dos critical legal studies (Penner, 2002) - que o direito não é, nem nunca foi, neutro.

Urge esclarecer que a ideia da protecção não é recente, quer no âmbito do direito substantivo, quer no âmbito do direito adjectivo (processual) em áreas tão diversas quanto o direito penal (Patrício, 2017) ou o direito da Família e dos Menores. Poderíamos trazer à colação também o exemplo da protecção da casa de morada de família ou do arrendatário, mas porque a pressão no sentido da competitividade do mercado laboral está em linha com a celeridade e autonomização do direito processual civil, considera-se que o paralelo mais rico a estabelecer será com a especial vulnerabilidade do trabalhador. Também a necessidade de combater a morosidade chegou ao direito processual do trabalho (Hespanhol, 2013) e criou necessariamente tensões com o princípio do tratamento mais favorável do trabalhador. É, pois, mais vasta esta preocupação com o equilíbrio entre os valores que o direito promove - dentro de uma concepção comum de justiça - e os atrasos que o elevado número de processos pendentes provocou no sistema de justiça, sem que contudo se procure definir qual o "tempo razoável" da justiça. A tensão é mais visível em áreas que implicam directamente com o funcionamento das empresas, inseridas, como vimos, em processos de aceleração temporal, em virtude dos já referidos processos de globalização.

Ficou demonstrada a centralidade do problema do "tempo da justiça" e a necessidade de reflexão crítica por parte de economistas e juristas, no sentido de se averiguar se a "nova" concepção de tempo não põe em perigo o ideal de justiça. É até compreensível que se reclame a propósito da exigência de eficiência por parte tribunais, não distinguindo entre eficiência e eficácia - a questão de saber qual a legitimidade do poder judiciário (Verzelloni, 2017). A administração da justiça - constitucionalmente atribuída aos tribunais - é diferente de uma gestão de conflitos com base em negociação e assente apenas em critérios de racionalidade económica. Neste caso, justificar-se-ia a retirada das situações de incumprimento dos créditos bancários da alçada dos tribunais - e da alçada da esfera pública - seguindo-se o modelo que nos EUA é assumido de forma pragmática como um modelo "power of sale", alternativa a um processo judicial. Veja-se o caso da Finlândia com um processo judicial que dura em média dois meses, uma redução significativa face à média europeia, mais próxima dos 24 meses (ECB, 2009).

Em suma, afirmar que a legislação é protectora apenas porque se insere numa família jurídica - de civil law ou direito continental - tida como protectora não pode ser acriticamente aceite. Um processo judicial time-consuming, que se arraste por 10 anos, pode não ser favorável, nem ser do interesse do executado (o devedor hipotecário). $\mathrm{O}$ atraso pode até não ter sido 
causado pelo devedor, pelo contrário, pode ser imputável ao exequente ou ao Agente de Execução, tal como um processo não-judicial nos EUA pode servir os interesses de um devedor do crédito à habitação devido à previsibilidade e transparência do desfecho.

$\mathrm{O}$ interesse por critérios de eficiência assentes no tempo está patente nos inúmeros artigos que mais recentemente sobre os problemas da justiça se debruçam, no âmbito das investigações levadas a cabo por Faculdades de Direito e não só (Lourenço, 2017; Silveira, 2017; Cabral, 2017; Gonçalves \& Guibentif, 2008; Gouveia, Garoupa, Magalhães, Carvalho, \& Félix, 2012). Poder-se-á afirmar que existe uma tendência para a desprotecção nas acções executivas em virtude dos processos de globalização e conexa aceleração do tempo? Valoriza-se o valor comercial do bem (casa) - e por isso se exige uma acção judicial - mas desconsidera-se o valor social que a casa representa como garantia de uma "equal citizenship" (Sassen, 2006)? É necessário avaliar criticamente a capacidade de intervenção do juiz na acção executiva. Pretende-se com este artigo fundamentar o potencial, também económico, de uma "justiça mais eficaz" que vá para lá de uma "gestão mais eficiente" da justiça (Carvalho, 2017), cumprindo assim os tribunais o desígnio da administração da justiça (artigo 202. ${ }^{\circ}$ da Constituição da República Portuguesa).

\subsection{A realização do direito e a vinculação do juiz à lei}

É desafiante verificar que mesmo os artigos especializados em habitação, na sua dimensão financeira, não ignoram as circunstâncias histórico- culturais para melhor captar a realidade social nas suas investigações empíricas. Embora não caiba aqui uma justificação pormenorizada da relação entre Estado e realização do direito - também envolvendo a implementação das políticas económicas do Estado - sempre invocaremos. J. Doling e R. Ronald (2010), na sua análise comparativa das diferentes europas, pois não ignoram os condicionalismos históricos para uma análise mais completa da habitação a propósito dos mecanismos de poupança e sistema de pensões: "differences exist in institutional arrangements and cultural practices between liberal regimes and Southern member states in terms of how housing assets may be turned into income. A perda da casa terá implicações mais ou menos dramáticas consoante o Estado pode ou não garantir o acesso à habitação por via da habitação social, o que varia consideravelmente nas "diferentes europas": "The remainder of the older member states of central and northern Europe (...) where social provision has generally been more developed (Doling \& Ronald, 2010).

Assim, também os sistemas legais - e os sistemas judiciais - terão de ser tidos em conta para uma mais completa análise da eficiência dos sistemas de habitação, pois necessariamente se encontram nos tribunais as consequências da dinâmica dos mercados - sobretudo nos

\footnotetext{
DINÂMIA'CET - IUL, Centro de Estudos sobre a Mudança Socioeconómica e o Território do Instituto Universitário de Lisboa (ISCTE-IUL)

Sala 2W4 - D | ISCTE-IUL - Av. das Forças Armadas 1649-026 Lisboa, PORTUGAL 
períodos recessivos - e se evidenciam as debilidades do Estado em assegurar a protecção face à perda da habitação, pois o Estado não consegue garantir outra habitação, pondo em causa o direito à habitação previsto no artigo 65. a Constituição da República Portuguesa.

Deste modo, se no relatório da UE se caracteriza o sistema continental como protector do devedor hipotecário por via da existência de um processo judicial, devemos questionar se a protecção do devedor hipotecário está patente, isto é, em primeiro lugar, perguntar 1) qual a função dos tribunais, tal como originalmente concebida na estrutura do Estado de direito? e 2) a prática judiciária revela essa protecção?

A origem e a construção do Estado moderno está profundamente imbricada na consolidação do rule of law, conforme afirma Unger (1977). Podemos definir o direito como uma "ordem de validade em que o homem se reconhece com uma irredutível dimensão ética" (Neves, 1993), mas teremos, antes de mais, de perceber como é que a prática do direito - a jurisprudência - realiza de facto o direito.

O rule of law - o império da lei - não é um conceito imutável, tem evoluído, começou por ser a afirmação de um espaço de liberdade perante o Estado e o seu ius imperii. Porém, esta ideia de que o Estado está vinculado a certos limites implicou a aceitação de que um certo número de direitos são invioláveis - os direitos fundamentais (Canotilho, 1994) e que agora se afirmam erga omnes (contra todos). De facto, o sentido concreto da validade que se constituiu historicamente foi variando e o direito foi, por isso, chamado a cumprir diferentes funções atendendo a contingências histórico-culturais diversas.

Historicamente, os pensamentos jurídicos romano, medieval, moderno-iluminista e o actual são muito diferentes quanto à intenção e quanto ao método. Defende Castanheira Neves (1993), que o direito já não tem como função legitimar uma ordem, ou justificar uma legalidade, tendo actualmente uma função de validade crítica - uma "reconstrução científico-reflexiva em que se assume uma intenção com sentidos fundamentantes que são o horizonte e a justificação da prática". Assim, a intencionalidade última do direito tem de estar patente na prática do direito na realização do direito - , por isso Castanheira Neves (1993) procura responder a duas questões essenciais: "que relação intencionalmente se estabelecerá concretamente entre o logos (a razão, a racionalidade e o pensamento) e o método (o modus ou o processo)? [e em segundo lugar] Que razão, racionalidade ou pensamento se terá especificamente de considerar". Se não respondermos cabalmente a estas questões outras ordens de legitimação se poderão impor, desde logo, a força ou o arbítrio pois não teremos conseguido encontrar o "fundamento ontológico que nos impedisse de ver no direito uma mera contingência ou arbítrio legislativo" (Neves, 1967) . Poderíamos até perguntar "por-quê o direito e não antes o não-direito?”. 
Também os sistemas de common law têm evoluído no sentido de questionar a sua metodologia e os seus pilares discutindo uma progressiva legitimidade dos tribunais na utilização de uma racionalidade legislativa que é "top-down" e "descend[s] imperialistically leading to a (...) remaking of practice in the light of the foundational view" (Conte, 2015).

Em suma, assume-se nos sistemas de common law que a lei adere necessariamente a uma vontade ideológica e por isso se considera que os sistemas de common law - a sua racionalidade jurídica - evolui verdadeiramente a partir da prática, conforme ideia expressa por Holmes na famosa frase" the life of the law has not been logic; it has been experience". Assim, trata-se da consagração de que o direito inglês é "the product of the work of practicioners, not of professors... of practical men, not of philosophers" (Conte, 2015).

É por isso de extrema importância, quer nos sistemas jurídicos de civil law quer nos de common law, perceber "what judges do, and what they say they do" (Conte, 2015; Posner, 2010). A zona de fronteira entre o poder judicial e uma alegada capacidade criadora (Lúcio, 2012) - para alguns já legislativa - é uma área sempre temida e por isso evitada ("an area in which angels fear to tread") (Conte, 2015).

Os tribunais estariam vocacionados para o caso concreto e não para a generalização abstracta própria da lei, pois estão vinculados ao direito existente e aos factos do caso ("judicial reasoning is by nature a posteriori concerned with the past, and specific") (Conte, 2015) . No entanto, é aceite que os juízes recorrem licitamente a analogias e a princípios estabelecidos na lei para encontrar e justificar decisões. Talvez para o civil law a capacidade criadora dos juízes possa ser entendida de outra forma, embora também não se aceite uma função legislativa dos juízes.

Na tarefa prática de realização do direito por via da decisão de casos concretos trazidos a juízo - os processos judiciais - é verdadeiramente clássica a polémica quanto à liberdade do juiz na aplicação da lei. Apresenta-se como argumento para a total vinculação do juiz à lei, o princípio da separação de poderes e o princípio da independência dos tribunais. São princípios que se complementam, pois o que se pretende, por um lado, é distanciar a função legislativa da função judicial para um melhor controlo de ambas e, por outro lado, assegurar a certeza jurídica que caracteriza a função judicial. Evitar-se-ia, assim, quer o "arbítrio estadual" quer “imprevisíveis inovações de jurisprudência” (Machado, 2004). Porém, a prática é a de que à jurisprudência é atribuída a missão de inovar - mesmo sem que existam alterações substanciais da lei - ao longo do tempo e em todas as áreas fundamentais. Deste modo, a prática demonstra que a visão tradicional do "papel dominante da lei e a função subordinada da jurisdição" não é a mais correcta (Machado, 2004), pois o recurso a conceitos indeterminados, por exemplo, permite este continuum de sentido dentro da norma. Para Baptista Machado (2004) o "núcleo" 
de sentido consistente, inequívoco e um «halo» de sentido, na zona mais imprecisa ou vaga, permitiriam esta capacidade de adaptação dos tribunais. Veja-se o caso paradigmático do artigo $10{ }^{\circ}$ do Código Civil em que, não existindo caso análogo, a questão terá de ser decidida segundo "a norma que o intérprete criaria se houvesse de legislar dentro do espírito do sistema". Entende-se, então, que a vinculação do juiz existe, é determinante, mas não é de um automatismo que se trata, pois o que está em causa, afinal, é do "escopo do princípio da vinculação à lei (...) [E] esse seria alcançado pela vinculação do juiz ao «direito jurisprudencial» e à dogmática jurídica” (Machado, 2004). A pretensão de validade apresentada pelo juiz é fundamentada discursivamente e assente na lei, ou seja, a fórmula legal não impede a chegada ao conteúdo de sentido. Em suma, o direito que vincula o juiz é um direito que também se constitui pelo direito jurisprudencial:

"E forçoso será ainda concluir que nenhuma lei pode determinar a evolução da jurisprudência já que toda e qualquer lei para a sua aplicação se tem de sujeitar à reelaboração jurisprudencial que a incorpora no «sistema de comunicação jurídica», tal como esta se constitui e desenvolve no contacto com a diversidade dos casos da vida real (Machado, 2004).

Nos sistemas de common law a possibilidade de uma racionalidade jurídica capaz de uma função de validade crítica também é discutida. Senão vejamos:

"For at least two reasons, the purity of the judicial reasoning process and adjudicative power must be preserved. The first is that judges are not democratically elected or externally accountable" (Conte, 2015).

No entanto, a aceitação de uma teorização sobre a prática jurídica - e judicial - parece ser mais aceite nos sistemas de civil law com a regular introdução de novas soluções por via legislativa. O caso emblemático da sentença do Tribunal Judicial de Portalegre (Portalegre, 2012) - ao decidir nos termos assim publicitados pela comunicação social, que "a entrega da casa liquida a dívida" surge como uma inovação face ao sentido de sentenças anteriores e recorre aos institutos de direito das obrigações "enriquecimento sem causa" e do "abuso de direito", acabando esta fundamentação por estar de acordo com o recurso largamente usado de facto nos EUA, como vimos, de não recorrer à possibilidade de perseguir os bens do devedor para além da casa (prohibition of deficiency judgement). No entanto, o mais relevante para a presente na análise é que esta decisão não foi tomada no âmbito de uma execução hipotecária, mas de uma acção declarativa (o processo-padrão, chamemos-lhe assim, e não o processo mais específico das ações executivas, conforme artigo $10{ }^{\circ}$ do Código de Processo Civil) e portanto, sem o acrescido espartilho processual a que as execuções hipotecárias estarão particularmente sujeitas. 
Em bom rigor, também o common law começa a questionar-se se o direito não estará necessariamente obrigado à criação jurisprudencial, estando esta vinculada à racionalidade jurídica e à vida - que é feita de situações novas:

"Three areas illustrate the point [it is quite impossible that law could exist at all without theory]: analogical reasoning, distinguishing precedents and judicial choice in novel cases" (Conte, 2015).

\section{CONCLUSÃO}

Os estudos econométricos classificam a legislação sobre execuções hipotecárias como protective for borrower e non-protective for borrower. Os estados protectores são os que exigem um processo judicial para a resolução do conflito entre credor e devedor hipotecários, quando este incumpre o empréstimo bancário. Surge, nessa altura a necessidade de saber qual o valor em dívida e se é possível chegar a um acordo para a manutenção do contrato, renegociando-o, ou se, após a determinação do valor em dívida, o devedor hipotecário entrega a casa - perde a casa - mas terá de se definir ainda se existe um remanescente da dívida por saldar.

Nos EUA cerca de $40 \%$ dos estados são "judicial", ou seja, protective for borrower e, apesar de não vigorar a proibição da possibilidade de perseguir judicialmente outros bens para além da casa (prohibition of deficiency judgement), este recurso é desincentivado por via do custo processual e, por isso, pouco usado.

Já na UE onde os estudos sobre o impacto da legislação sobre execuções hipotecárias são escassos, assume-se que a protecção que se confere ao devedor hipotecário também é garantida pela obrigatoriedade de um processo judicial e pela duração deste - alargando o período em que poderá renegociar o contrato com o credor hipotecário, não perdendo a casa.

Porém, se os processos de globalização impõem um ritmo acelerado (de tempos curtos) também na administração da justiça - nas execuções hipotecárias - pode ter de se concluir que a aceleração, como um fim em si mesmo, esboroa o tempo da justiça, o tempo "razoável" que o direito a si impõe (artigo 2. ${ }^{\circ}$ do Código de Processo Civil).

Precisamos, então, de recorrer à filosofia do direito para clarificar a função dos tribunais que administram a justiça em nome do povo (artigo 202. ${ }^{\circ}$ da Constituição da República Portuguesa) e de que forma fica esta ameaçada.

Defende Castanheira Neves (1993) que o direito é "uma específica ordem de validade em que o homem se reconhece com uma irredutível dimensão ética", pelo que os tribunais terão

\footnotetext{
DINÂMIA'CET - IUL, Centro de Estudos sobre a Mudança Socioeconómica e o Território do Instituto Universitário de Lisboa (ISCTE-IUL)

Sala 2W4 - D | ISCTE-IUL - Av. das Forças Armadas 1649-026 Lisboa, PORTUGAL 
hoje já não a função de legitimar uma ordem ou constituir uma legalidade mas - com o seu sistema de valores, princípios fundamentantes e estruturas institucionais específicas -, mas cada vez mais uma "função de validade crítica".

De acordo com esta tese, a realização do direito sofre um ataque quando não se permite a sua função crítica, retirando-se a capacidade de intervenção efectiva do juiz - quer pela aceleração processual, quer permitindo o afastamento de facto do executado (o devedor hipotecário), pois não é obrigatória a constituição de um advogado oficioso (caso não se apresente outro nos autos), quer pela instauração de um automatismo processual (também já presente na Administração Fiscal (Portes \& Marques, 2015)), quer pela entrega de uma parte importante da tramitação (desde logo a elaboração do Auto de Penhora) ao Agente de Execução, em certo sentido, um mecanismo de outsourcing da justiça pouco debatido no espaço público (vide, no entanto, notícia do jornal DN de 07 de Março de 2017 "Encontrada morta pelos agentes executores de ordem de despejo - Família não pagava prestações do empréstimo da casa ao banco. Vítima ter-se-á suicidado").

É necessário o envolvimento dos tribunais em mais estudos interdisciplinares tendo em vista a análise dos processos para um melhor conhecimento dos mesmos (Pizarro Beleza, 2010), neste caso, da defesa efectiva do devedor hipotecário, aquando da execução. A academia não pode aceitar acriticamente a afirmação de que o civil law é mais protector do que o common law nas execuções hipotecárias.

Conforme ensina Menezes Cordeiro, a proibição da prisão por dívidas foi um passo importante na evolução do direito das obrigações, pois na tradição jurídica de Roma, o credor tinha o poder de esquartejar e escolher os membros do devedor com que se pretendia ressarcir, desde que proporcionais à dívida (Cordeiro, 2012). Parece-nos agora pouco racional tal solução jurídica, mesmo que a duração do processo nessa altura fosse mais consentânea com o mundo globalizado de hoje (mais célere).

As mudanças profundas - as rupturas a que assistimos no que à financeirização do mercado de habitação e à fungibilidade da propriedade diz respeito - só se tornam inteligíveis quando a desagregação social (Polanyi, 2016) se torna evidente e difícil de reverter, nomeadamente, na ruptura dos vínculos de pertença ao Estado, com a chancela dos tribunais. As rupturas sociais profundas acontecem sempre, ensina Polanyi, perante "a estupefacção dos espíritos sensatos" (Polanyi, 2016). 


\section{REFERÊNCIAS}

ALVES, N., \& Ribeiro, N. (2011). Modelação do Incumprimento dos Particulares. Relatório de Estabilidade financeira, Banco de Portugal, Lisboa.

AMBrose, B. W., Buttimer, R. J., \& Capone, C. A. (1997). Pricing Mortgage Default and Foreclosure Delay. Journal of Money, Credit and Banking, 29(3), 314-325. Obtido em 15 de Junho de 2017, de http://www.jstor.org/stable/2953696

ARENDT, H. (2005). A Promessa da Política. Relógio d’Água.

BdP. (2009). Financial Stability Report, 2008. Lisboa: Banco de Portugal. Obtido em 2 de Janeiro de 2017, de https:/www.bportugal.pt/sites/default/files/anexos/pdfboletim/ref_08_e.pdf

BENTO, V. (2011). Economia, moral e política. Lisboa: FFMS e Relógio d'Água.

BERRY, M. D. (2010). Mortgage default in Australia: nature, causes and social and economic Impact. RMIT Research Centre. Melbourne: Australian Housing and Urban Research Institute.

BOURDIEU, P. (2012). Sobre o Estado - Curso no College de France (1989-1992). Edições 70 .

BRAMLEY; Munro; Pawson. (2004). Key issues in housing: policies and markets in 21 st century Britain. Palgrave Macmillan.

CABRAL, C. C. (2017). Justiça: desempenho, custos e financiamento. Em 40 Anos de Políticas de Justiça em Portugal (pp. 541-574). Almedina. 
CAMPILHO, T. G. (2011). Incumprimento do Contrato de Mútuo Para Aquisição de habitação e Adjudicação do Imóvel Hipotecado por Valor Inferior ao da Dívida Exequenda. Tese de Mestrado, Escola de Direito da Universidade Católica Portuguesa.

CANOTILHO, J. (1994). Constituição Dirigente e Vinculação do Legislador Contributo Para a Compreensão das Normas Constitucionais Programáticas. Coimbra Editora.

CAPONE, C. A. (1996). Providing Alternatives to Mortgage Foreclosure: A Report to Congress. U.S. Department of Housing and Urban Development.

CARVALHO, J. M. (2017). A organização dos tribunais e a profissão de juiz. Em 40 Anos de Políticas de Justiça em Portugal (pp. 311- 330). Amedina.

CLAURETIE, T. M. (1987). The Impact of Interstate Foreclosure Cost Differences and the Value of Mortgages on Default Rates. AREUEA Journal, 15(3), 152-168.

CLAURETIE, T. M., \& Herzog , T. (1990). The Effect of State Foreclosure Laws on Loan Losses: Evidence from the Mortgage Insurance Industry. Journal of Money, Credit and Banking, 22(2), 221-233. Obtido em 5 de Jnho de 2017, de http://www.jstor.org/stable/1992309

Código de Processo Civil. (2013).

CONTE, C. (2015). From only the "Bottom-up"? Forms of Judicial Reasoning in Private Law. Oxford Journal of Legal Studies, 35, 1-30.

CORDEIRO, A. M. (2012). Tratado de Direito Civil. Almedina.

CUTTS, A. C., \& Merrill , W. A. (2008). Interventions in Mortgage Default: Policies and Practices to Prevent Home Loss and Lower Costs. Joint Center for Housing Studies, Havard University. 
DN. (7 de Março de 2017). Encontrada morta pelos agentes executores de ordem de despejo. Diário de Noticias (DN). Obtido em 7 de Março de 2017, de http://www.dn.pt/sociedade/interior/encontrada-morta-pelos-agentes-executores-deordem-de-despejo-5709415.html

DOLING, J., \& Ronald, R. (2010). Home ownership and asset-based welfare.

ECB. (2009). Housing Finance in the Euro Area, March 2009, Task Force of the Monetary Policy Committee of the European System of Central Banks . European Central Bank.

EXPRESSO. (21 de Março de 2015). Vítor Reis. "É assustador o que o Estado gastou no crédito bonificado". Obtido em 21 de Março de 2015, de http://expresso.sapo.pt/economia/vitor-reis-e-assustador-o-que-o-estado-gastou-nocredito-bonificado=f916096

FLEISHMAN, S. (2 de Fevereiro de 2002). Facing Foreclosure. Washington Post February 2. Obtido em 02 de Junho de 2017, de https://www.washingtonpost.com/archive/realestate/2002/02/02/facingforeclosure/5199b265-bda6-4717-84d8-e8a436eb3636/?utm_term=.578f777ca40d

FRADE, C. (2015). O perdão de dívidas na insolvência das famílias. Em A. C. Santos, Famílias endividadas - uma abordagem de economia política e comportamental (pp. 133-146). Coimbra: Almedina.

FRADE, C., Lopes, C., Jesus, F., \& Ferreira, T. (2008). Um perfil dos sobreendividados em Portugal. Coimbra: Centro de Estudos Sociais da Faculdade de Economia da Universidade de Coimbra (CES).

GONÇALVES, M. E., \& Guibentif, P. (2008). Novos Territórios do Direito Europeização, Globalização e Transformação da Regulação Jurídica. Princípia Editora. 
GOODMAN, A. C., \& Smith, B. C. (2010). Housing Default: Theory Works and So Does Policy, Working Paper . (10-10).

GOUVEIA, M., Garoupa, N., Magalhães, P., Carvalho, J., \& Félix, S. (2012). Justiça Económica em Portugal - Consulta de processos judiciais, uma análise econométrica. (F. F. Santos, Ed.) Fundação Francisco Manuel dos Santos.

GUARDIAN, T. (26 de Agosto de 2015). The right to buy: the housing crisis that $\begin{array}{llllll}\text { Thatcher } & \text { built. } & \text { Obtido de }\end{array}$ https://www.theguardian.com/society/2015/aug/26/right-to-buy-margaret-thatcherdavid-cameron-housing-crisis

GUISO , L., Sapienza , P., \& Zingales, L. (2009). Moral and Social Constraints to Strategic Default on Mortgages, Working Paper. (15145).

HESPANHOL, M. J. (2013). Crise Económica e o Tempo da Justiça: Os Recursos e o Processo Laboral. Julgar, 21, 151-158.

LEFEBVRE, H. (2011). O direito à cidade. Centauro Editora.

LEITÃO, L. M. (2015). O impacto da crise financeira no regime do crédito à habitação. Julgar, 25, 49-63.

LEVINAS, E. (2011). Totalidade e Infinito. Um ensaio sobre a Exterioridade. Biblioteca de filosofia contemporânea.

LOURENÇO, P. M. (2017). Processo executivo. Em 40 Anos de Políticas de Justiça em Portugal (pp. 227-249). Almedina.

LÚCIO, Á. L. (2012). O Julgamento - Uma narrativa crítica da justiça (2a ed.). Publicações D. Quixote. 
MACHADO, B. J. (2004). Jurisprudência. Em Pólis, Enciclopédia da Sociedade e do estado (pp. 842-850). Verbo.

MARQUES, M. F. (2004). Regular o Sobreendividamento. Observatório do Endividamento dos Consumidores. Faculdade de Economia, Universidade de Coimbra.

MEADOR , M. (1982). The Effects of Mortgage Laws on Home Mortgage Rates. Joumalof Economic and Business, 34, 143-148.

MIAN, A., Su, A., \& Trebbi, F. (2009). The Political Economy of the U.S. Mortgage Default Crisis. Obtido de http://ssrn.com/abstract=1291524

NEVES, A. C. (1967). Questão-de-facto - Questão-de-direito ou o Problema Metodológico da Juridicidade. Coimbra: Livraria Almedina.

NEVES, A. C. (1993). Metodologia jurídica: problemas fundamentais. Coimbra Editora.

PATRÍCIO, R. (2017). Processo penal: quatro décadas de avanços e recuos no due process of law. Em 40 Anos de Políticas de Justiça em Portugal (pp. 199-212). Almedina.

PENCE, K. (2003). Foreclosing on Opportunity: State Laws and Mortgage Credit. Federal Reserve Board Finance and Economics Discussion Series No. 16.

PENNER, J. (2002). Textbook on Jurisprudence (4th ed.). McCoubrey \& White`s.

PITTINI, A., Ghekiere, L., Dijol, J., \& Kiss, I. (2015). The State of Housing in the EU 2015. Brussels: Housing Europe, The European Federation for Public Coperative and Social Housing. 
PIZARRO Beleza, T. (2010). Direito das mulheres e da igualdade social: a construção jurídica das relações de género. Almedina.

POLANYI, K. (2016). A Grande Transformação - As Origens Políticas e Económicas do nosso Tempo. Edições 70.

PORDATA. (2015). Conhecer a Crise. Obtido em 12 de Outubro de 2015, de http://www.conheceracrise.com/indicador/63/no-de-pessoas-com-emprestimo-emincumprimento

PORTALEGRE, T. J. (2012). Decisão Judicial de 04-01-2012: Entrega da casa ao banco liquida dívida. Obtido de www.inverbis.pt

PORTES, A., \& Marques, M. M. (2015). Valores, Qualidade Institucional e Desenvolvimento em Portugal. Fundação Francisco Manuel dos Santos.

POSNER, R. (2010). How judges think. Harvard University Press.

RAWLS, J. (1971). Por uma Teoria da Justiça. (C. P. Correia, Trad.) Lisboa: Editorial Presença.

SANTOS, A., Teles, N., \& Serra, N. (2014). Finança e habitação em Portugal. (CES, Ed.) Cadernos do Observatório.

SASSEN, S. (2006). Territory, Authority, Rights: from medieval to global assemblages. Princeton University Press.

SASSEN, S. (2017). Predatory Formations Dressed in Wall Street Suits and Algorithmic Math. Science, Technology \& Society, 22, 1-15.

SILVEIRA, J. T. (2017). A (falta de) gestão nos tribunais. Em 40 Anos de Políticas de Justiça em Portugal (pp. 505-529). Almedina. 
SPANG-HANSSEN, H. S. (2009). Foreclosure of Real Estate - Ideas from a different legal system (Denmark). Social Science Research network Electronic (SSRN). Obtido de http://ssrn.com/abstract=1414525

STREECK, W. (2011). The Crises of Democratic Capitalism. In: New Left Review (71). MPHG Journal, 5-29.

THE GUARDIAN. (26 de Agosto de 2015). theguardian. Obtido em 09 de Dezembro de 2015, de https://www.theguardian.com/society/2015/aug/26/right-to-buy-margaretthatcher-david-cameron-housing-crisis

UNGER, R. M. (1977). Law In Modern Society - Toward A Criticism Of Social Theory. The Free Press Paperback.

VERZELLONI, L. (2017). A gestão dos sistemas de justiça, governo dos tribunais numa análise comparada. Em 40 Anos de Políticas de Justiça em Portugal (pp. 579600). Almedina.

VICENTE, F. L. (2013). The Effect of Foreclosure Regulation: Evidence for the US Mortgage Market at State Level. Banco de Espanha( 1306).

VILLEY, M. (2005). A formação do pensamento jurídico moderno. Martins Fontes.

WIEACKER, F. (2010). História do Direito Privado Moderno (trad. de A. M. Botelho Hespanha). Fundação Calouste Gulbenkian. 